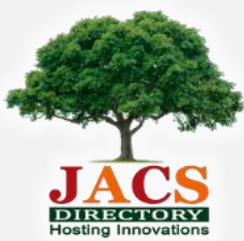

Journal of Nanoscience and Technology

Visit Journal at http://www.jacsdirectory.com/jnst

\title{
Eco-Friendly Microwave Assisted Approach: Synthesis of CdO/Polyacrylonitrile and CdO/ Poly(Butyl Methacrylate) Nanocomposites and Their Thermal Studies
}

\author{
Devendra Kumar*, Hari Shankar \\ Department of Chemistry, Institute of Basic sciences, Dr. Bhimrao Ambedkar University, Khandari Campus, Agra - 282 002, Uttar Pradesh, India.
}

\section{AR T I C LE D E T A I LS}

\section{Article history:}

Received 23 May 2019

Accepted 10 June 2019

Available online 13 June 2019

\section{Keywords:}

Polyacrylonitrile

Poly(Butyl Methacrylate)

Microwave-Assisted Synthesis

\begin{abstract}
A B S T R A C T
CdO nanoparticles, polyacrylonitrile, poly(butyl methacrylate) polymers have been synthesized by using green chemistry approach. Thereafter synthesized polymers were fabricated into nanocomposites by mixing nanoparticles to the polymers again using green chemistry protocol. Formation of CdO nanoparticles was confirmed by FT-IR and UV-Visible spectral data. The sizes of nanoparticles were determined by P-XRD and TEM analysis. P-XRD and TEM images of nanoparticles indicated that size of most of the nanoparticles lies in the range $5.74-22.25 \mathrm{~nm}$. Formation of polymers and nanocomposites was confirmed by IR spectral studies. Morphology of nanocomposites was determined by SEM analysis. The thermal stability of polymers and nanocomposites was determined by TGA/DTA and found that the thermal stability of CdO/PAN \& CdO/PBMA nanocomposites increased as compared to their polymers.
\end{abstract}

\section{Introduction}

In recent years nanotechnology has attracted researchers due to their diversified applications almost in all areas of human life such as aircraft sector [1], electronics, environmental remediation [2], food [3] and medical health sector $[4,5]$. Nanotechnology has ability to build materials at nano range [6]. In fact, the properties of substances dramatically change when their size is reduced to the nanometer range $[7,8]$ as nanometer range particles have high surface to mass ratio [9]. In last few years, the development of polymer nanocomposites has offered new technology and favorable opportunities for commercial scale as well as all over society [10]. Dispersion of nanoscale fillers into polymer matrix to form a nanocomposite has attracted great interest [11]. These fillers not only enhance their performance but also exhibited new physical properties and novel behavior as compared to neat polymer matrix [12]. Inorganic nanoparticles-based nanocomposites display very interesting applications such as thermal [13], electrical [14], mechanical [15], optical properties [16] and environmental remediation [17]. The influence on thermal stability of polymers by addition of $\mathrm{CdO}$ nanoparticles in polymer matrix has been earlier reported by researchers. Thermal stability of poly vinyl alcohol (PVA) increased by doping of CdO nanoparticles [18]. CdO/ Polyaniline (PANI) nanocomposites are more thermal stable than the PANI polymer [19]. With the increasing awareness towards the environmental safety, researchers are ready to commence the eco-friendly approach for the synthesis of nanoparticles and nanocomposites. In recent years microwave assisted synthesis has become very popular as this technique offers simple, clean, fast, efficient, economic and environmentally friendly nature compared to conventional heating method $[20,21]$. In this context, in continuation of our research work [22,23] in this article we have reported the synthesis of cadmium oxide (CdO) nanoparticles, two polymers viz. polyacrylonitrile [PAN], poly(butyl methacrylate) [PBMA] and their CdO/PAN and CdO/PBMA nanocomposites by adopting green chemistry protocol to observe the influence of nanoparticles on the thermal stability of polymers.

\section{Experimental Methods}

\subsection{Synthesis of CdO Nanoparticles}

2.30 g cadmium (II) acetate dihydrate was dissolved in $15 \mathrm{~mL}$ deionised water. To this solution, $0.75 \mathrm{~g}$ starch dissolved in $20 \mathrm{~mL}$ deionised water

\section{*Corresponding Author:devendrakumar131@gmail.com(Devendra Kumar)}

was added. The mixture was irradiated in a microwave synthesizer at 110 $\mathrm{W}$ for $3 \mathrm{~min}$ by maintaining the temperature $70{ }^{\circ} \mathrm{C}$. Now, $10 \mathrm{~mL}$ ammonia solution was added drop by drop to the above solution with constant stirring. The solution was further irradiated for 2 min at $110 \mathrm{~W}$. A yellow colour precipitate was obtained which was allowed to settle down for overnight. It was filtered washed with deionised water to remove byproducts and excessive starch and calcined at $600{ }^{\circ} \mathrm{C}$ for $3 \mathrm{~h}$.

\subsection{Synthesis of Polyacrylonitrile [PAN]}

$5 \mathrm{~mL}$ acrylonitrile was taken in a round bottom flask. To this solution, $10 \mathrm{mg}$ benzoyl peroxide and $10 \mathrm{~mL}$ toluene were mixed. The contents of the flask were heated in a microwave synthesizer at an emitted power of $90 \mathrm{~W}$ for $2 \mathrm{~min}$ by maintaining the temperature $60{ }^{\circ} \mathrm{C}$. The precipitation was done by using acidified $\mathrm{CH}_{3} \mathrm{OH}\left(1 \mathrm{~mL} \mathrm{HCl}+5 \mathrm{~mL} \mathrm{CH}_{3} \mathrm{OH}\right)$ and then uniformly spread on a glass plate. A powder form product was obtained.

\subsection{Synthesis of Poly(Butyl Methacrylate) [PBMA]}

In a $100 \mathrm{~mL}$ round bottom flask, $5 \mathrm{~mL}$ butyl methacrylate, $10 \mathrm{mg}$ benzoyl peroxide and $10 \mathrm{~mL}$ toluene were mixed. This mixture was irradiated in a microwave synthesizer at an emitted power of $90 \mathrm{~W}$ for 4 min at $60{ }^{\circ} \mathrm{C}$. The precipitation was done by using acidified $\mathrm{CH}_{3} \mathrm{OH}(1 \mathrm{~mL}$ $\mathrm{HCl}+5 \mathrm{~mL} \mathrm{CH}_{3} \mathrm{OH}$ ) and then homogeneously spread on a glass plate. A thin film was obtained on drying.

\subsection{Synthesis of CdO/Polyacrylonitrile Nanocomposite [CdO/PAN]}

In a $100 \mathrm{~mL}$ round bottom flask, $5 \mathrm{~mL}$ acrylonitrile and $10 \mathrm{mg}$ benzoyl peroxide were taken and $10 \mathrm{~mL}$ toluene was added. The contents of the flask were subjected with microwaves at an emitted power of $100 \mathrm{~W}$ for 4 min by maintaining the temperature at $65^{\circ} \mathrm{C} .0 .05 \mathrm{mg}$ cadmium oxide nanoparticles suspended in water: $\mathrm{HCl} \mathrm{(1:3)} \mathrm{was} \mathrm{added} \mathrm{in} \mathrm{the} \mathrm{sticky} \mathrm{state}$ of polyacrylonitrile. The heating was continued in the microwave synthesizer for $4 \mathrm{~min}$. The precipitation was done by using acidified $\mathrm{CH}_{3} \mathrm{OH}\left(1 \mathrm{mLHCl}+5 \mathrm{~mL} \mathrm{CH} \mathrm{CH}_{3} \mathrm{OH}\right)$ and then uniformly spread on a glass plate. A powdered material was obtained on drying in a desiccator over anhydrous $\mathrm{CaCl}_{2}$.

\subsection{Synthesis of CdO/Poly(Butyl Methacrylate) Nanocomposite [CdO/PBMA]}

$5 \mathrm{~mL}$ butyl methacrylate was taken in a $100 \mathrm{~mL}$ round bottom flask. To this, $10 \mathrm{~mL}$ benzoyl peroxide and $10 \mathrm{~mL}$ toluene were added. The contents were subjected for microwave irradiation in a microwave synthesizer at $100 \mathrm{~W}$ for $7 \mathrm{~min}$ by maintaining the temperature at $65^{\circ} \mathrm{C} .0 .05 \mathrm{mg}$ of cadmium oxide nanoparticles suspended in water: $\mathrm{HCl}(1: 3)$ was added in

\footnotetext{
(a)
} 
the viscous solution of poly(butyl methacrylate). The solution was again heated for $8 \mathrm{~min}$. Finally, the precipitation was done by using acidified $\mathrm{CH}_{3} \mathrm{OH}\left(1 \mathrm{~mL} \mathrm{HCl}+5 \mathrm{~mL} \mathrm{CH}_{3} \mathrm{OH}\right)$ and spread over a glass plate. On drying at room temperature, a thin film was obtained.

\subsection{Characterization Studies}

Microwave synthesizer Discover Lab Mate with Intellivent Pressure, $240 \mathrm{~V} / 50 \mathrm{~Hz}$ has been used to synthesize nanoparticles and nanocomposites. FT-IR spectroscopic studies were carried out in the range $4000-400 \mathrm{~cm}^{-1}$ on 'Bruker' spectrophotometer by using $\mathrm{KBr}$ pellets. UVVisible spectroscopic study was carried out on Lab-India UV-Visible spectrophotometer UV $3000^{+}$in DMSO at room temperature. The P-XRD analysis was carried out on XPERT-PRO X-ray diffractometer operated at a voltage of $45 \mathrm{kV}$ and a current of $40 \mathrm{~mA}$ with $\mathrm{Cu} \mathrm{K} \alpha$ radiation $(\lambda=0.15418$ $\mathrm{nm})$ in $10-80^{\circ}$ scanning range. The TEM studies were carried out on model CM200, operated at an accelerating voltage of $20-200 \mathrm{kV}$ with the resolution 2.4 A. The Scanning Electron Microscopic studies has been carried out on JEOL Model JSM-6390LV operating and resolution of $3 \mathrm{~nm}$ (Acc V30 kV, WD $8 \mathrm{~mm}, \mathrm{SEI}$ ) to $8 \mathrm{~nm}$ (Acc V $1.0 \mathrm{kV}$, WD $6 \mathrm{~mm}, \mathrm{SEI}$ ) and magnification $5 \times$ to $300,000 \times$ (both in high and low vacuum modes), operating at a voltage of $1 \mathrm{pA}$ to $1 \mathrm{~mA}$. The TGA/DTA analysis was carried out on model Perkin Elmer USAA, Diamond TG/DTA and TGA measurement range was $200 \mathrm{mg}$ and sensitivity $0.2 \mathrm{mg}$.TG/DTA and TG measurement range vary from $30^{\circ} \mathrm{C}$ to $750^{\circ} \mathrm{C}$ at $10^{\circ} \mathrm{C} / \mathrm{min}$.

\section{Results and Discussion}

\subsection{FT-IR Spectral Studies}

IR spectra of synthesized cadmium nanoparticles exhibited peaks at $652.55 \mathrm{~cm}^{-1}$ and $449.92 \mathrm{~cm}^{-1}$ due to Cd-O bond. The appearance of these bands indicated that cadmium nanoparticles have been formed in the form of CdO nanoparticles [24, 25]. IR spectra of polyacrylonitrile [PAN] and cadmium oxide/polyacrylonitrile [CdO/PAN] nanocomposite exhibited bands in the range 2937.20-2887.45 $\mathrm{cm}^{-1}$ due to $-\mathrm{C}-\mathrm{H}$ stretching vibrations of $-\mathrm{CH}_{2}$ [26], 2243.36-2243.32 $\mathrm{cm}^{-1}$ due to $-\mathrm{C} \equiv \mathrm{N}$ stretching vibrations, $1452.36-1451.04 \mathrm{~cm}^{-1}$ due to $-\mathrm{C}-\mathrm{H}$ bending vibrations of $\mathrm{CH}_{2}$ and 1352.94-1226.86 $\mathrm{cm}^{-1}$ due to bending vibrations of $\mathrm{C}-\mathrm{H}$ moiety [26]. A strong band in the region 1178.64-1073.06 $\mathrm{cm}^{-1}$ has been attributed due to stretching vibrations of $\mathrm{C}-\mathrm{C}$ moiety $[26,27]$. Some new bands 538.21 and $464.64 \mathrm{~cm}^{-1}$ also appeared in the spectra of cadmium oxide/polyacrylonitrile [CdO/PAN] nanocomposite which may be attributed due to Cd-O deformation vibrations.

IR spectra of poly(butyl methacrylate) [PBMA] and cadmium oxide/poly(butyl methacrylate) [CdO/PBMA] exhibited the bands at 2957.61-2928.99 $\mathrm{cm}^{-1}$ due to $\mathrm{C}-\mathrm{H}$ stretching vibrations [28] of $\mathrm{CH}_{3}$, 2932.30-2737.96 $\mathrm{cm}^{-1}$ due to $\mathrm{C}-\mathrm{H}$ stretching vibrations of $\mathrm{CH}_{2}$, 1721.38$1720.48 \mathrm{~cm}^{-1}$ due to $\mathrm{C}=0$ stretching vibrations $[28,29], 1466.15-1455.91$ $\mathrm{cm}^{-1}$ due to $\mathrm{C}-\mathrm{H}$ bending vibrations of $\mathrm{CH}_{2}, 1146.15-1142.26 \mathrm{~cm}^{-1}$ due to $\mathrm{C}-$ $\mathrm{O}-\mathrm{C}$ stretching vibrations and band near $1063.22-1020.19 \mathrm{~cm}^{-1}$ may be attributed due to stretching vibrations of C-C bonds. In the IR spectra of [CdO/PBMA] new bands appeared at $517.48 \mathrm{~cm}^{-1}$ and $462.24 \mathrm{~cm}^{-1}$ which may be attributed due to $\mathrm{Cd}-0$ deformation vibrations respectively.

\subsection{UV-Visible Spectral Studies}

The UV-Visible spectra (Fig. 1) of cadmium oxide nanoparticles exhibited peaks at $291 \mathrm{~nm}$ and $315 \mathrm{~nm}$ which confirm [30, 31] the formation of cadmium oxide nanoparticles.

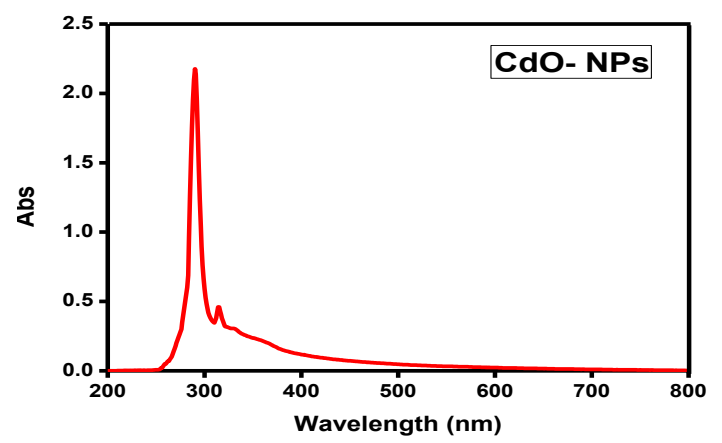

Fig. 1 UV-Visible spectra of CdO nanoparticles

\subsection{P-XRD Studies}

The XRD spectra (Fig. 2) of the cadmium oxide nanoparticles exhibited that the synthesized nanoparticles were crystalline in nature. The size https://doi.org/10.30799/jnst.272.19050414 distribution of nanoparticles was determined by full width at half maximum (FWHM). The broader is the size distribution of the particles, the broader is the peak [32]. The crystalline size of nanoparticles was calculated by using the width of X-ray peaks, supposing they are free from non- uniform strains, using Debye - Scherrer's formula.

On applying Debye-Scherrer formula on different peaks of P-XRD graph (Fig. 2) of cadmium oxide nanoparticles it has been found that the synthesized nanoparticles have different size like 4.24, 5.18, 15.53, 15.52, $12.42,6.21,8.87,20.70,20.70,15.53,8.87 \mathrm{~nm}$. The average particle size of synthesized cadmium oxide nanoparticles has been found to be $12.16 \mathrm{~nm}$.

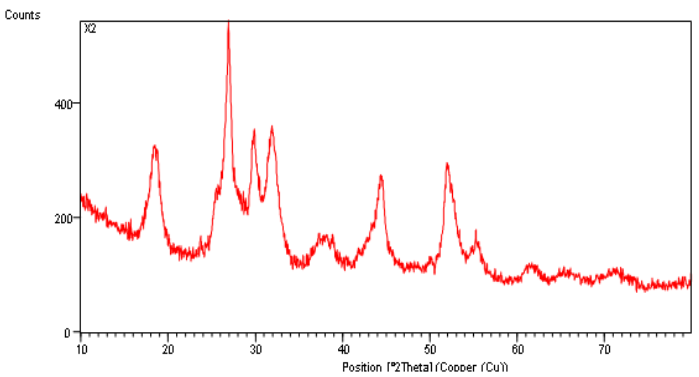

Fig. 2 P-XRD graph of CdO nanoparticles

\subsection{Transmission Electron Microscopic Studies}

The transmission electron microscopic (TEM) images (Fig. 3) clearly indicated that the particle size of synthesized cadmium oxide nanoparticles lies in the range $5.74-22.25 \mathrm{~nm}$. The average size of cadmium oxide nanoparticles was $14.33 \mathrm{~nm}$.
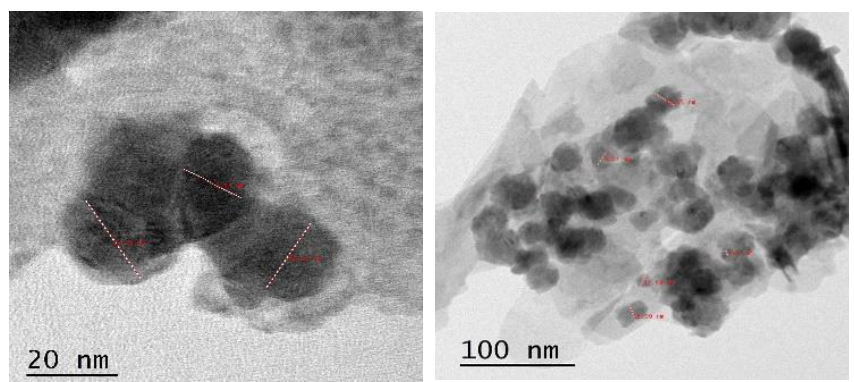

Fig. 3 TEM images of synthesized CdO nanoparticles

\subsection{Scanning Electron Microscopic Studies}

The SEM images (Fig. 4) of CdO/PAN nanocomposite showed flaked plate morphology with irregular shape [33] and SEM images (Fig. 5) of CdO/PBMA nanocomposite showed the crack path with good dispersion of CdO nanoparticles in PBMA matrix [34].
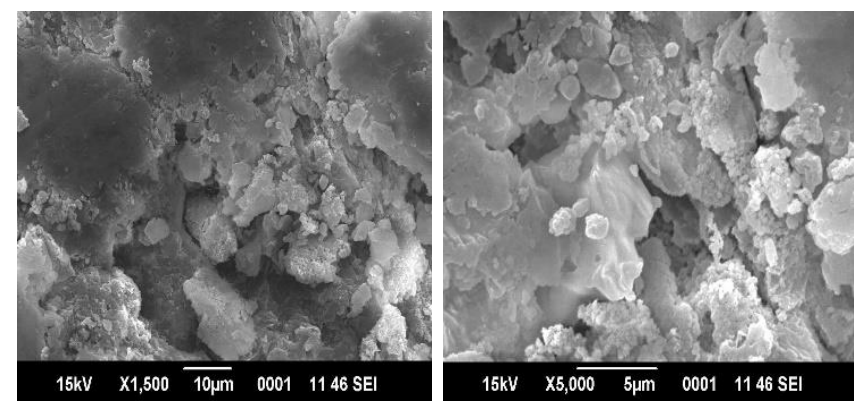

Fig. 4 The SEM images of CdO/PAN nanocomposite
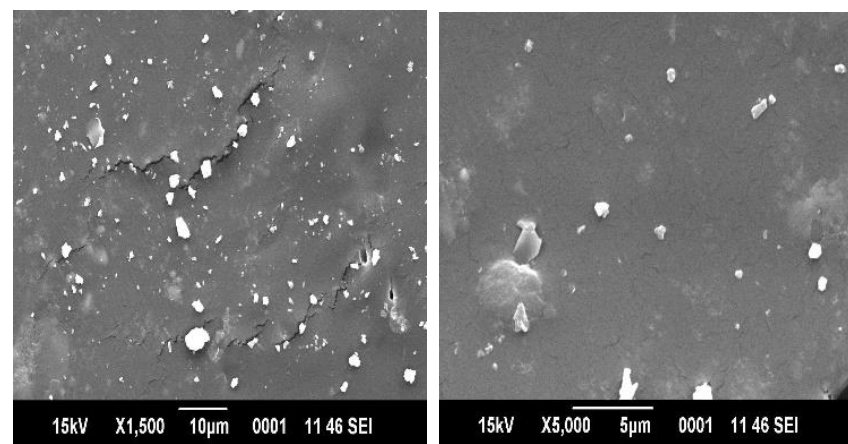

Fig. 5 SEM images of CdO/PBMA nanocomposite 


\subsection{Thermogravimetric Analysis}

TG/DTA thermograms (Fig. 6) of polyacrylonitrile [PAN] indicated its degradation in 3 steps. In the first step degradation occurred between $114.40-184.10^{\circ} \mathrm{C}$ corresponding to weight loss $10.120 \%$, second weight loss was found between $235.20-318.86{ }^{\circ} \mathrm{C}$ corresponds to weight loss $42.160 \%$, third weight loss was found between $346.46-400.50{ }^{\circ} \mathrm{C}$ corresponds to weight loss $47.457 \%$. DTA thermogram indicated that these weight losses were accompanied by endothermic change.
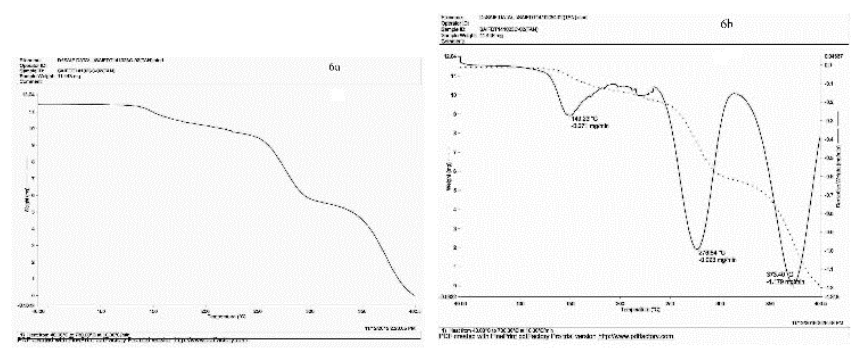

Fig. 6 TG/DTA thermograms of polyacrylonitrile

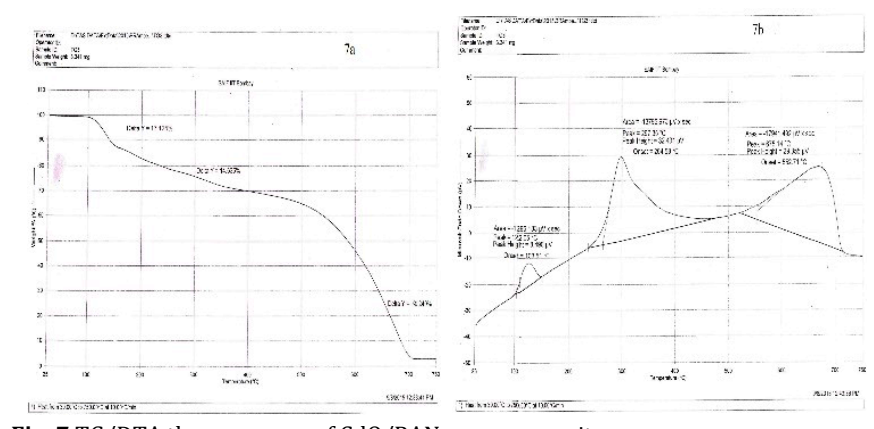

Fig. 7 TG/DTA thermograms of CdO/PAN nanocomposite

TG/DTA thermograms (Fig. 7) of CdO/PAN indicated its degradation in 3 steps. In the first step nanocomposite degradation occurred between $75.35-213.75{ }^{\circ} \mathrm{C}$ corresponding to weight loss $17.125 \%$ while second weight loss was found between $213.75-380.85{ }^{\circ} \mathrm{C}$ corresponds to weight loss $14.635 \%$. Third weight loss $60.240 \%$ was observed between 638.43 $711.85^{\circ} \mathrm{C}$ with exothermic change.

TG/DTA thermograms (Fig. 8) of the PBMA polymer indicated two step thermal degradation. This first step degradation occurred between 106.68- $322.10{ }^{\circ} \mathrm{C}$ corresponds to weight loss of $84.832 \%$ with endothermic change. Second step degradation occurred $322.10-422.10^{\circ} \mathrm{C}$ corresponds to weight loss of $15.151 \%$ with exothermic change.
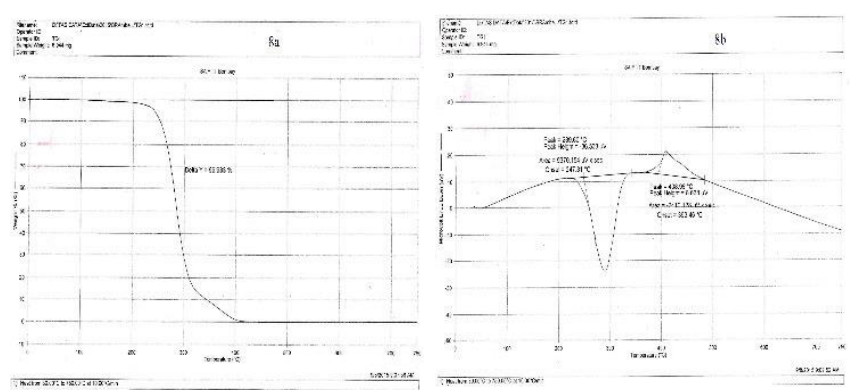

Fig. 8 TG/DTA thermograms of poly butyl methacrylate

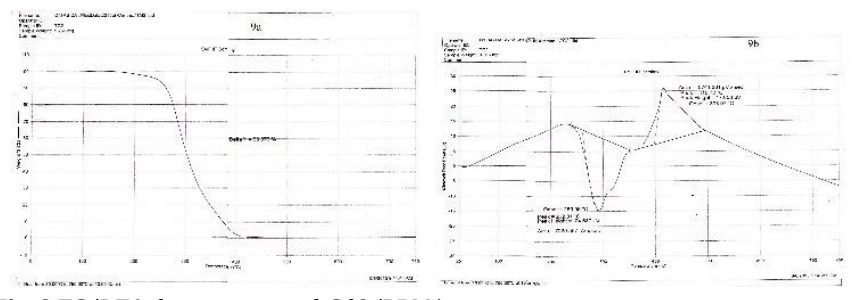

Fig. 9 TG/DTA thermograms of CdO/PBMA nanocomposite

TG/DTA thermograms (Fig. 9) of the CdO/PBMA nanocomposite indicated two step thermal degradation. This first step degradation occurred between $139.15-345.76{ }^{\circ} \mathrm{C}$ corresponding to weight loss of $72.263 \%$ with endothermic change. Second degradation occurred between $345.76-463.76{ }^{\circ} \mathrm{C}$ corresponding to weight loss $27.716 \%$ with exothermic change.
On comparing the thermograms of nanocomposites with their polymers it has been found that the thermal stability of PAN and PBMA polymer increases on incorporation of $\mathrm{CdO}$ nanoparticles in polymer matrixes. This can be explained by the manner that the increase in thermal stability could be due to strong interaction and interfacial bonding between the polymer matrix and $\mathrm{CdO}$ nanoparticles [35].

\section{Conclusion}

CdO nanoparticles, PAN, PBMA polymer and their nanocomposites were successfully synthesized by adopting green and efficient microwave assisted approach. XRD results revealed that the average size of nanoparticles was $12.16 \mathrm{~nm}$ which was very close to the average particle size $14.33 \mathrm{~nm}$ obtained by TEM. The nanocomposites CdO/PAN and CdO/PBMA exhibited greater thermal stability as compared to their polymers which may be due to strong interaction and interfacial bonding between the polymer matrix and $\mathrm{CdO}$ nanoparticles.

\section{Acknowledgement}

The authors gratefully acknowledge the DST-FIST for providing funds for FT-IR and UV spectrophotometer. We would also like to thank (SAIF) Punjab University, Chandigarh for P-XRD studies, SAIF, Cochin, Kerala for providing TEM and SEM studies and (SAIF) IIT Bombay for TG/DTA studies.

\section{References}

[1] I. Kumar, Nanocraft-an aircraft with nanotechnology, Int. J. Res. Appl. Sci. Eng Technol. 3(2) (2015) 1-6.

[2] P.G. Tratnyek, R.L. Johnson, Nanotechnologies for environmental cleanup, Nanotoday 1(2) (2006) 44-48.

[3] R. Ravichandran, Nanotechnology applications in food and food processing: Innovative green approaches, opportunities and uncertainties for global market, Int. J. Green Nanotechnol. Phys. Chem. 1(2) (2010) 72-96.

[4] S.A. Wickline, G.M. Lanza, Nanotechnology for molecular imaging and targeted therapy, Circulation 107(8) (2003) 1092-1095.

[5] H.L. Wong, X.Y. Wu, R. Bendayan, Nanotechnological advances for the delivery of CNS therapeutics, Adv. Drug Deliv. Rev. 64 (2012) 686-700.

[6] M.P.M. Garcia, M.C.G. Guillen, M.E.L. Caballero, G.V. Barbosa-Canovas, Edibile film and coatings Fundamentals and Applications, 1st Edn., CRC Press, Washington, 2017.

[7] P. Mishra, R. Jain, Electrochemical deposition of $\mathrm{MWCNT}-\mathrm{MnO}_{2} / \mathrm{PPy}$ nanocomposite application for microbial fuel cells, Int. J. Hydrogen Energy 41(47) (2016) 22394-22405.

[8] B.H. Patel, D.P. Chattopadhyay, Nano-particles and their uses in textiles, The Indian Textile J. 118(3) (2007) 23-31.

[9] J. Biener, A. Wittstock, T. F. Baumann, J. Weissmüller, M. Bäumer, A.V. Hamza, Surface chemistry in nanoscale materials, Materials 2(4) (2009) 2404-2428.

[10] P.H.C. Camargo, K.G. Satyanarayana, F. Wypych, Nanocomposites: Synthesis, structure, properties and new application opportunities, Mat. Res. 12(1) (2009) 1-39.

[11] X. Cao, Y. Habibi, L.A. Lucia, One-pot polymerization, surface grafting, and processing of waterborne polyurethane-cellulose nanocrystal nanocomposites, J. Mater. Chem. 19(2009) 7137- 7145.

[12] S. Kondawar, R. Mahore, A. Dahegaonkar, S. Agrawal, Electrical conductivity of cadmium oxide nanoparticles embedded polyaniline nanocomposites, Adv. Appl. Sci. Res. 2(4) (2011) 401-406.

[13] T.M. Al-Saadi, E.E. Al-Abodi, A.J. Zaier, A. Farouk, A.F. Sulaiman, Preparation, characterization and thermal analysis of polymeric blend nanocomposites based on PVA-PVPPEG doped with zinc oxide nanoparticles, ARPN J. Eng. Appl. Sci. 13(9) (2018) 3246-3250.

[14] D.K. Rana, S. K. Singh, S.K. Kundu, S. Roy, S. Angappane, S. Basu, Electrical and room temperature multiferroic properties of polyvinylidene fluoride nanocomposites doped with nickel ferrite nanoparticles, New J. Chem. 43 (2019) 3128-3138.

[15] A. Naim, N. Alnaim, S.S. Ibrahim, S.M. Metwally, Effect of gamma irradiation on the mechanical properties of PVC/ZnO polymer nanocomposite, J. Radiat. Res. Appl. Sci. 10(3) (2017) 165-170.

[16] H.K. Inamdar, B.C. Sridhar, M. Sasikal, M.V.N.A. Prasad, Structural and optical properties of polypyrrole/NiO doped nanocomposites, J. Nanosci. Tech. 4(3) (2018) 400-401.

[17] J.Zhu, S. Wei, M. Chen, H. Gu, S. B. Rapole, S. Pallavkar, T.C. Ho, J. Hopper, Z. Guo, Magnetic nanocomposites for environmental remediation, Adv. Powder Technol. 24(2013) 459-467.

[18] J. Selvi, S. Mahalakshmi, V. Parthasarathy, Synthesis, structural, optical, electrical and thermal studies of poly(vinyl alcohol)/CdO nanocomposite films, J. Inorg. Organomet. Polym. 27 (2017) 1918-1926.

[19] H. Gulce, V. Eskizeybek, B. Haspulat, F. Sari, A. Gulce, A. Avci, Preparation of a new polyaniline/CdO nanocomposite and investigation of its photocatalytic activity: comparative study under UV light and natural sunlight irradiation, Ind. Eng. Chem. Res. 52(32) (2013) 10924-10934 
[20] S.V. Kumar, A.P. Bafana, P. Pawar, A. Rahman, S.A. Dahoumane, C.S. Jeffryes. High conversion synthesis of $<10 \mathrm{~nm}$ starch-stabilized silver nanoparticles using microwave technology, Sci. Reports 8(1) (2018) 51-10.

[21] A. Verma, R. Dwivedi, R. Prasad, K.S. Bartwal, Microwave assisted synthesis of metal oxide nanoparticles, J. Nanopart. 2013 (2013) 1-11.

[22] D. Kumar, A. Jain, Neelam, Green chemistry approach: Synthesis, characterization and thermal studies of nanocomposites of lead oxide nanoparticles, J. Chem. Pharm. Res. 8(10) (2016) 86-93.

[23] D. Kumar, N. Sharma, Neelam, Green and rapid approach for the synthesis of $\mathrm{CuO} /$ polyacrylonitrile and $\mathrm{CuO} /$ polymethyl methacrylate nanocomposites and their thermal stability, J. Indian Chem. Soc. 95 (2018) 617-622.

[24] A. Tadjarodi, M. Imani, H. Kerdari, K. Bijanzad, D. Khaledi, M. Rad, Preparation of $\mathrm{CdO}$ rhombus-like nanostructure and its photocatalytic degradation of azo dyes from aqueous solution, Nanomater. Nanotechnol. 4 (2014) 1-9.

[25] D.D. Vijaykarthik, M. Kirithika, N. Prithivikumaran, N. Jeyakumaran, Synthesis and characterization of cadmium oxide nanoparticles for antimicrobial activity, Int. J. Nano Dimens. 5(6) (2014) 557-562.

[26] S. Lee, J. Kim, B.C. Ku, J. Kim, H.I. Joh, Structural evolution of polyacrylonitrile fibers in stabilization and carbonization, Adv. Chem. Eng. Sci. 2(2012) 275-282.

[27] R.F. Ribeiro, L.C. Pardini, N.P. Alves, C.A.R.B. Junior, Thermal stabilization study of polyacrylonitrile fiber obtained by extrusion, Polímeros. 25(6) (2015) 523-530.
[28] N. Pekel, O. Guven, Fourier transform infrared-photoacoustic spectroscopy of poly(N-butyl methacrylate) adsorbed from solution on alumina, J. Appl. Polym. Sci. 69(8) (1998) 1669-1674.

[29] S. Qin, D. Qin, W.T. Ford, D.E. Resasco, J.E. Herrera, Polymer brushes on singlewalled carbon nanotubes by atom transfer radical polymerization of n-butyl methacrylate, J. Am. Chem. Soc. 126(1) (2004) 170-176.

[30] K.M. Prabu, P.M. Anbarasan, S. Janarthanan, G. Sivakumar, Preparation and characterization of CdO nanoparticles by precipitation method, Int. J. Sci. Res. Dev. 2(11) (2015) 368-370.

[31] A.K. Barve, S.M. Gadegone, M.R. Lanjewar, R.B. Lanjewar, Synthesis and characterization of CdO nanomaterial and their photocatalytic activity, Int. J. Recent Innovat. Trends Comp. Commun. 2(9) (2014) 2806- 2810.

[32] R. Srivastava, D. Kumar, Antibacterial Study of Metal Nanoparticles, 1st Edn., Lap Lambert Academic Publishing, Germany, 2012.

[33] K. Ayyasamy, S. Palanisamy, P. Kandasamy, S. Chitra, Polyester-bentonite clay composite: Synthesis, characterization and application as anticorrosive agent, Orient, J. Chem. 31(3) (2015) 1811-1821.

[34] K. Liu, Tungsten carbide - processing and applications, In Tech, Croatia, 2012.

[35] D. Vaishnav, R. K. Goyal, Thermal and dielectric properties of high-performance polymer/ZnO nanocomposites, Mater. Sci. Eng. C 64 (2014) 1-10. 